Bacteriology.-Fortunately $\mathrm{B}$. Welchii is not a strict anaerobe, and therefore its culture is a matter of ease. On each occasion all I had at my disposal were two blood agar slopes; on the first, I made a slope culture, and in the second a stab culture with a platinum loop, taking my material from the vitreous without contamination from the conjunctival sac. Heath in a similar manner was able to cultivate his anaerobe.

I wish to thank Mr. Juler and Mr. Foster Moore for their kind permission to report these cases, also Dr. S. H. Browning for the bacteriological examinations and $\mathrm{Mr}$. Heath for permission to discuss his case in conjunction with my own.

\title{
REFERENCES
}

Chaillous.-Recueil d'Ophtal., p. 678, 1904.

\begin{tabular}{l} 
Ann.d'Ocul., p. 115, 1905. \\
Darier._La Clin. Ophtal., p. 266, 1905. \\
\hline La Clin. Ophtal., p. 227, 1906
\end{tabular}

Heath.-Brit. Jl. of Ophthal., p. 574, 1929.

James.-Ophthal. Rev., p. 161, 1910,

Trans. Ophthal. Soc. U.K., p. 179, 1910.

Lutz.-K'in. Monatsbl.f. A ugenheilk., p. 311910.

Medical Research Committee.- Report upon anaerobic bacteria and infections.

Oreste.-Ann. d'Ocul., p. 35. 1910.

Ridley.-Trans. Ophthal. Soc. U,K., p. 221, 1929.

Schumacher.-Ann. d'Ocul., p. 303, 1908.

Williams.-Brit. Jl. of Surgery, Vol. XIV, p. 295, 1926-27.

\section{ON LOOKING FOR HOLES IN DETACHED RETINA}

BY

\section{J. BRUCE Hamiliton}

LONDON

ONE evening after a colleague and I had spent much time searching for a possible hole in a detached retina and had failed, he uttered the following aphorism : "There is only one thing more tedious than looking for a hole oneself, and that is watching someone else looking for it."

It had been my fortune-good or bad-during the past eight months to search for holes in well over sixty detachments that have entered Moorfields Eye Hospital for ignipuncture, and as the detection of holes has apparently come to be an essential investigation in the art of the modern ophthalmic surgeon, I feel, after my experiences, that I might offer a little help and advice.

The finding of a hole is the sine qua non of Professor Gonin's operation of ignipuncture, and I believe that he and his assistants are prepared to spend an hour daily for many days engaged in the search. It is impossible for a busy British oculist to spend so 
much of his time in the quest for a hole, and therefore the following may speed his labour:-

I divide my detachments into two classes:-

1. Those in which I do not expect to find a hole.

(a) First we must remember that a not uncommon cause of detachment is sarcoma of the choroid and therefore a neoplasm must always be kept in mind. I believe that several patients with sarcomas have been sent halfway across Europe for ignipuncture only to be returned with a polite note. I admit that in the first enthusiasm of hole searching one quite easily overlooks this fact.

(b) There are the inflammatory detachments which are shallow, have a pinkish complexion and have not the same tendency to white billows as myopic detachments have. The vessels look dark red rather than black, while sometimes exudate is to be seen on the surface.

2. Those in which I expect to find a hole.

This group includes the myopic and the traumatic detachments, or a combination of both. It is in these that much time must be expended in searching and in that search I want to offer a word of encouragement.

(a) History.-A careful history is often of much value in hole finding. Always ask in what part of the field the visual loss was first appreciated.

One patient-a male Jew-with a left temporal detachment, related that four days previously, while at a picnic, he thought he saw a foreign body on the left side of his nose halfway between the bridge and the tip. So certain was he that one was present that he asked a friend to remove it and was surprised to hear that no foreign body was to be found. The next day the vision in the eye commenced to fail. When he told me this history four days later I immediately looked at 2 o'clock in the periphery of the retina and there found the smallest hole I have ever seen. It was certainly no wider than a retinal artery and not more than $\frac{1}{3} \mathrm{~mm}$. in length. Without this clear history I much doubt whether I should ever have found this hole.

(b) Dilated pupil.--So far I have never seen a hole behind the equator of the globe but I believe they do occur. Consequently, I find it essential for the pupil to be fully dilated and then it is quite possible either with the direct or indirect method of ophthalmoscopy to see as far forward as the ora serrata. Personally, I always use the direct method with a Lister-Morton electric ophthalmoscope, for I find some holes-as in the case of the Jew mentioned previously-too small to see without high magnification. I believe Professor Gonin uses the indirect method with a condensing lens of 16 dioptres. 
(c) Types of hole.-There are three main groups :-

(1) Tears at the ora serrata which are often only detected by the contrast of their white folded posterior edge and the lesser white of the main detachment. This is their shape.

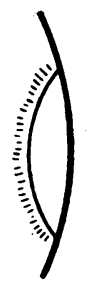

(2) Small round holes which appear as if they had been punched out by a ticket inspector. These are often associated with old choroiditis and are usually to be found about one to one and a half disc diameters from the ora serrata. I might conveniently mention here that the diameter of a normal optic disc is $1 \frac{1}{2} \mathrm{~mm}$. and that we use, when measuring space on the retina, a disc diameter as our standard distance. Later we convert our measurement into millimetres.

(3) Horse-shoe rents which are usually found in cases with a traumatic history and vary tremendously in size. The largest hole I have seen was a horse-shoe one and it extanded from 6 o'clock to 2 and back to 6 again.

(d) Old choroiditis.-When talking about type (2) holes I mentioned old choroiditis. I believe all searchers for holes have been struck by the presence of old peripheral choroiditis in eyes with detachments, and more especially by the fact that the holes in the detachments when found have been closely associated with or surrounded by pigment. If, therefore, one finds such a patch of old choroiditis, its vicinity should be diligently scrutinized and possibly much time will be saved.

(e) Multiple holes.-These are by no means uncommon and it is this fact which makes hole hunting so laborious. Unless every hole is detected it is far better that none is found, for it is useless to cauterise one hole when others remain undetected. Further, without doubt I have seen fresh holes appear after an operationholes which were not present before the puncture was done. Therefore it is all-important that the retina be thoroughly explored before the operation, so that one can be sure that certain holes are secondary. These secondary holes usually appear as rents at the ora serrata.

(f) Position of detachment.-(1) Above. I have invariably found 
that if the detachment is above, the hole is there also, but sometimes the hole lies behind a fold and cannot be seen with ease. In such a case the patient should be ordered three to four days in bed, when the detachment will probably change in size and possibly in position so that the hole or holes are seen with ease.

(2) Lateral and medial.--If the detachment is localised to a medial or lateral position then one can be fairly sure that the hole is on that side, and usually in the upper third of the detachment.

(3) Below.-As most detachments usually settle to this position it is difficult to say, when it is seen for the first time and is below, where the hole will be found. It may quite possibly be in the detachment itself, but often I find them quite apart in a portion of the retina which appears to be completely in position.

Failure.-If at first one fails to detect a hole, then as I have said before, the patient should be put to bed for three to four days and another attempt made. Change in body position for a short time often means change in detachment position. Sometimes a hole lies behind a fold or billow, and by rest is brought into view. But I do not advocate a posterior sclerotomy with the intention of altering the shape of the detachment, for the risk of making an artificial hole in the retina is a real one.

Fallacies.-(a) Atrophy of the retina. Sometimes the retina which is detached appears so atrophic in patches that the unwary mayo mistake such patches for holes. Personally, I feel that these patches are so atrophic that fluid from the vitreous can penetrate through them and therefore they are potential holes. But this is only my own opinion.

(b) A cleft below.-It is usual when the detachment lies below that it is divided into two symmetrical portions by a deep cleft in the mid-line of the eye. I have discussed this cleft with Miss Mann and she feels that it may be due either to pressure of the hyaloid canal or else to the firmer attachment of the retina to the choroid at the site of the foetal cleft. Whatever be the theory of the origin of this cleft, the fact is that as it looks red and the billowy retina on each side looks white it may be mistaken for a hole.

(c) Aphakic eyes.-And now a last word on aphakic eyes with detached retinae. These detachments usually occur some thirty to forty years after needling for lamellar cataract, and I think that finding holes in them is quite a superhuman feat, but it is not totally impossible, for in one I was able to see no less than three holes, but I must admit that they were found before I saw the case. 